\title{
NOTA DE LA DIRECTORA DE LA REVISTA
}

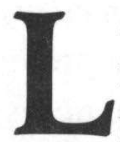

a Revista Análisis pretende ser un instrumento de reflexión, información, discusión y de examen crítico de la realidad puertorriqueña y latinoamericana. Les dará la oportunidad a estudiantes, docentes y practicantes del trabajo social de exponer sus experiencias prácticas y los resultados de sus investigaciones. Iniciamos este primer número con ocho artículos de la Facultad de la Escuela Graduada de Trabajo Social.

El primer artículo, del profesor Víctor Iván García Toro, gira en torno a la educación en trabajo social y los retos que ésta confronta en la actualidad. García Toro le da énfasis al compromiso de la educación con los desafíos que la propia circunstancia histórico-académica le exige y finaliza con las tendencias a ser consideradas en el desarrollo de currículos en trabajo social. Los cuatro artículos que le siguen están relacionados con la práctica profesional. Nos presentan información valiosa sobre programas de intervención con familias y la criminalidad. La profesora Milagros Lizardi nos describe un programa de fortalecimiento familiar como alternativa al maltrato de menores, que funciona en la ciudad de Mayagüez desde 1996. Discute el modelo de intervención utilizado en el programa, la incorporación del componente de investigación para evaluar su efectividad y los logros del mismo. La profesora Sheila Archilla expone sobre el Multimétodo Empírico utilizado en el Proyecto de Servicios Integrales de Preservación y Apoyo Familiar, que funciona en la Regiones de Bayamón, Carolina y San Juan de la Administración de Familias con Niños del Departamento de la Familia.

El artículo de la profesora Gloria Molina discute un modelo de intervención con mujeres jefas de familia que se lleva a cabo en el Programa de Apoyo Familiar a Niños y Adultos en el municipio de 
Gurabo. Se presentan también los logros obtenidos en la implantación de este modelo. La profesora Blanca Hernández analiza la criminalidad desde la perspectiva del trabajo social. Específicamente examina las implicaciones de la política pública en torno a la criminalidad para la práctica de trabajo social.

El segundo tema de este primer número, bajo el cual aparecen tres artículos, es la investigación. La profesora Cynthia RodríguezParés diserta sobre el porqué y para qué de la investigación científica en la Escuela Graduada de Trabajo Social. El artículo de la profesora Diana Valle Ferrer informa los resultados de un estudio de necesidades de las familias en Puerto Rico; y cómo esos resultados son utilizados para el desarrollo de un Plan Estratégico de Cinco Años para un Programa de Servicios de Apoyo y Fortalecimiento de las Familias. En este artículo se demuestra como la investigación impacta el proceso de elaboración de la política social. El último artículo de este número, de la profesora Nilsa $M$. Burgos Ortiz junto a las profesoras Milagros Bravo y Mary Clare Lennon, explica los resultados de una investigación sobre los síntomas de depresión en mujeres solteras con jefatura de familia, comparadas con mujeres casadas o solteras que no son jefas de familia; la vulnerabilidad a eventos estresantes; y las redes de apoyo emocional e instrumental en término de su tamaño y calidad. Además, se discute las implicaciones de esta investigación para las profesiones de ayuda.

Al final se presentan tres reseñas de nuevos libros de la facultad de trabajo social publicados recientemente. Las mismas son de los libros Pioneras de la profesión de trabajo social en Puerto Rico, de la profesora Nilsa M. Burgos Ortiz; El trabajo social en Puerto Rico: ¿Asistencia, desarrollo o transformación? de la profesora Dagmar Guardiola y Violencia en la familia ... una perspectiva crítica, editado por las profesoras Diana Valle Ferrer, Lillian Albite Vélez e Islia Rosado López.

Nilsa M. Burgos Ortiz 